\title{
O corpo na ópera': alguns apontamentos
}

\section{Resumo}

Talvez seja desde a utilização do termo Gesamtkunstwerk por Richard Wagner que a ideia de ópera como espetáculo total tenha sido inexoravelmente incorporada ao seu significado. Entretanto, há questões importantes que interferem na produção, realização e encenação da ópera com forte ligação com a encenação teatral. Dentre essas questões está a afirmação comum de que a expressão da técnica vocal pode ser prejudicada pelas ações corporais. Todavia, as novas gerações de cantores líricos ainda em formação parecem opor-se a esta perspectiva. Buscam uma formação teatral sólida e abrem-se para diversas experiências corporais. Isto tende a demonstrar não apenas uma disponibilidade para a encenação, mas aponta para valores e conceitos sobre o espetáculo operístico.

Palavras-chave: Ópera; corpo; encenação

The body at the opera: some appointments

\section{Abstract}

Perhaps it is since the use of the term Gesamtkunswerk, by Richard Wagner, that the idea of opera as a total artwork have been inexorably merged to its meaning. However, there are important issues that affect the staging of opera as a which are strongly connected to theatre staging. Among the many issues, one is related to the staging possibilities of each singer, once it's usual to state that the expression of vocal technique can be hindered by the bodily actions. Nevertheless, new generations of lyric singers, still studying, seem to oppose to this view. This tends to demonstrate not only a disposition to the stage, but point to values and concepts on the operatic show.

Key-words: Opera, body, staging

A questão do corpo no teatro é bastante recorrente e ainda é comum encontrarmos reflexões sobre qual deve ser o treinamento do ator para que ele esteja disponível e preparado para a encenação. No caso da ópera o corpo parece ainda obedecer à ideia de corpo instrumental: o corpo que produz a voz. O corpo que, tal qual um instrumento, deve estar estável para a produção do que é esperado em relação à técnica vocal. Ainda é comum encontramos comentários publicados ou declarados que justificam e valorizam a ideia de que o corpo do cantor deve mover-se de modo a

\footnotetext{
${ }_{1}$ Projeto regular apoiado pela Fapesp 2011/2012

2 Doutora em pedagogia do Movimento Humano pela Unicamp. Docente do curso Ciências da Atividade Física na Escola de Artes, Ciências e Humanidades da Universidade de São Paulo. Preparadora Corporal do Núcleo Universitário de Ópera
} 
não prejudicar o canto a tal ponto que muitos críticos tendem a condenar as encenações nas quais o corpo do cantor é, na verdade, um corpo cênico.

Mais do que o conceito de encenação em ópera, parece que o problemático é a concepção de corpo que é difundida pelo senso comum e que tende a influenciar a formação de artistas para o gênero, assim como a expectativa do público e da produção.

Para a jovem cantora lírica Angélica Menezes, a encenação na ópera brasileira é cercada por mitos:

Um dos grandes desafios - possivelmente o maior deles - para o cantor
lírico é encontrar a tal verdade cênica. As razões são várias: quase sempre
o cantor tem formação musical apenas, e não cênica. Muitos acreditam
que a verdade cênica está em "agir naturalmente"; que a voz, nesse caso
a qualidade vocal, bastaria para transmitir a tal verdade. Tendo a voz como
eixo principal da encenação, a atuação fica relegada a um segundo plano.
Os gestos, as ações não são senão estereótipos que se confundem com
realismo. Outros ainda pregam que cantor não é ator e que sua voz não
pode ser sacrificada de forma alguma. Há a crença - infundada - de que a
movimentação atrapalharia a boa fluência da voz. Crença antagônica, já que
a voz é produzida pelo corpo. E, dessa forma, palavra e ação física caminham
em separado; um não justifica o outro. Muitos encenadores defendiam que a
ação antecede a palavra, e a ação começa no corpo. A problemática dessa
busca poderia ser justificada pela falta de elementos, de técnica corporal
por parte dos cantores (a questão já levantada de que as escolas de canto
focam-se na música, quase exclusivamente) e pelo desinteresse de muitos
em obtê-los. A formação corporal do cantor deveria ser a mesma do ator, já
que ele o é (MENEZES, 2011, comunicação pessoal)

Talvez seja desde a utilização do termo Gesamtkunstwerk por Richard Wagner que a ideia de ópera como espetáculo total ou coletivo, ou, ainda, comum (PICON-VALLIN, 2008) tenha sido inexoravelmente incorporada ao seu significado, especialmente na Europa. Para Dudeque (2009) esse conceito se reflete na acepção de que o verdadeiro drama só pode ser concebido quando várias formas de arte comunicam-no coletivamente, no entendimento mútuo e na cooperação inteligível de entre as variedades artísticas. A proposta de Wagner, tanto conceitual quanto artística, apresentou um conjunto de inovações na dramaturgia e na cena do que se convencionou chamar ópera - e que o próprio Wagner optou por denominar posteriormente drama musical - modificaram a relação entre o espectador e a cena, entre o real/cotidiano e o teatral.

Foi Adolphe Appia quem identificou, no entanto, que o projeto wagneriano esbarrou em equívocos marcados, provavelmente, pelo seu tempo, demonstrados em suas produções. Dudeque (2009) afirmou que para Appia estava claro que, por um lado, a música e o texto wagneriano gozavam de liberdade sobre as convenções da realidade, mas, por outro, a encenação dos seus dramas ainda seguiam as normas da 
convenção do teatro de sua época. Isso trouxe para Appia a necessidade de descrever o que denominou problemas essenciais da concepção wagneriana:

\footnotetext{
1. Wagner criou um novo tipo de drama onde a sua força expressiva baseia-se na vida interior dos personagens e que estes são suficientes para a localização espacial da ação dramática; 2. as óperas de Wagner eram representadas com os tradicionais panos de fundo pondo em contradição o ator como um ser vivo e uma cenografia que tentava representar ou criar a ilusão de um ambiente. No entanto, as indicações cênicas supérfluas mantiveram o drama wagneriano preso à visão realista de seus contemporâneos. Apesar de ter renovado a estrutura dramática, Wagner manteve a representação tradicional. (DUDEQUE, 2009, p.9).
}

Appia aponta para a ação dramática como fundamento decisivo para o teatro, destacando o ator como elemento central. Para ele, influenciado pelas ideias de Dalcroze, o ator treinado em dança e ritmo seria capaz de representar a música no corpo vivo do ator, já que é nele que é expressa toda emoção que procuramos (DUDEQUE, 2009).

É interessante verificarmos que as posições sobre a encenação centrada na preparação do ator em Appia partem da reflexão sobre o contexto operístico. O ator (que canta) é o centro de toda a encenação e o seu corpo precisa ser treinado de modo a constituir-se como espaço de encenação, livre dos maneirismos e gestos realistas copiados do mundo real. Como afirmou Picon-Vallin (2008), assim como em Appia, a ópera constituiu-se como um laboratório importante também no teatro russo, especialmente para a reflexão sobre a música no teatro.

Tratando especificamente da importância destes elementos e sobre o papel da ópera na materialização dessa lógica de encenação, Beatrice Picon-Vallin (2006) explicou que Meierhold concebia a música quase como uma 'substância' da ação, e por este motivo seria adequado que o encenador abordasse a ópera não a partir do libretto, mas da partitura, de seu espírito e de seu ritmo. Para o encenador é a sua estrutura composicional que dita os jogos de cena. Como consequência, para o artista da ópera, as suas ações seriam compostas pelas ondas rítmicas dos movimentos corporais, quase uma dança, o que amplia o potencial expressivo da palavra e da música. Isso é especialmente importante já que na ópera o tempo é estendido pela música, de modo distinto da palavra falada ou mesmo da pantomima. Por essa razão Meierhold considerava o potencial da ópera uma experiência inigualável para qualquer ator e imaginava poder ensaiar uma peça inteiramente apoiada numa composição musical, já que considerava que a música era o melhor organizador do tempo de um espetáculo. Para ele o ator não deveria ilustrar a música, mas revelá-la e completá-la, numa intrincada concordância rítmica (PICON-VALLIN, 1999). 
Meierhold não foi o único a considerar a ópera uma experiência importante e um espetáculo com grande potencial cênico: Stanislavski, Grotowski, Appia, Craig, Artaud e Brook referiram-se à ópera, encenaram montagens. Outros tantos autores apontam a estreita relação entra a encenação e a música como pontos determinantes para a ópera (ATKINSON, 2006, CASOY, 2009, PEIXOTO, 1986 para citarmos apenas alguns) e isso se reflete na busca de referenciais para a pesquisa e atuação por alguns artistas no Brasil, como foi o caso de Guse (2009).

No entanto, ainda persistem críticas importantes manifestadas pelos teatrólogos e encenadores sobre o universo operístico: o culto à personalidade, apontado por Roubine (1998), a paralisação em função do bel canto descrita por Stanislavski (STANISLAVSKI E RUMYANTSEV, 1998), o excesso de exibicionismo apontado por Brook (1999). Questões que, se retornamos o depoimento de Menezes no início deste texto parecem estar vivas na formação e na crença de alguns.

Outra questão evidente, e que é parte do cotidiano da ópera, é bem ilustrada no relato de Atkinson (2006) sobre a atitude de um encenador da Welsh Opera Company ao modificar suas propostas cênicas (consideradas criativas e interessantes) já que os cantores declararam não poder realizar as ações físicas sob pena de prejudicarem a voz cantada.

No ano de 2009, durante a montagem do Núcleo Universitário de Ópera (NUO) para a ópera El hijo fingido, do compositor espanhol Joaquin Rodrigo sobre texto do dramaturgo Lope de Vega, os cantores dançaram uma composição coreográfica baseada no flamenco contemporâneo numa das cenas intermediárias da ópera. Para isso prepararam-se durante meses e aprenderam técnicas de sapateado e de movimentação do flamenco. Essa ação coreográfica foi, de fato, elemento da preparação corporal para aquela montagem. Embora o "tom" da montagem não buscasse a precisão de um bailaor ou bailaora flamencos, a ideia estava em trazer ao público e aos integrantes toda a dinâmica própria daquela dança. Além disso, não estavam no palco os bailaores, ou os cantores, mas as personagens do texto original, concebidas pelo encenador a partir do libretto e da música e que foram construídas ao longo dos ensaios.

Assistindo a um dos ensaios gerais uma das responsáveis pela administração do teatro onde a companhia se apresentou, e que tem vasta experiência com coros estáveis no país, imediatamente apontou: não imagino os integrantes 'daqueles' coros fazendo isso. Mais ainda: dispondo-se a fazer. Naquele momento ela relembrou um 
episódio no qual os integrantes de um coro estável importante no país negaram-se a atender às solicitações do encenador durante uma montagem de ópera: "somos cantores" - esbravejaram em uníssono - "não dançarinos"! O encenador cedeu.

Embora seja consenso de que a ópera é teatro e que, por consequência, o cantor deve preparar-se como um ator e ainda que seja clara a afirmação de que não há mais lugar na ópera para aquele que possui apenas uma bela voz (CASOY, 2009), há uma dúvida persistente sobre o limite do potencial cênico do cantor. Tomando o exemplo anterior podemos nos perguntar: em qual medida aqueles cantores estavam disponíveis para a encenação? Até que ponto ele pode encenar sem prejuízo para o canto?

No entanto, não é apenas em relação aos cantores que há resistência à inovação no material da ópera e em sua encenação. No início do século XX a montagem de Meierhold para Dama de Espadas, de Tchaikóvski, causou escândalo devido à adaptação feita no libretto e aos cortes na partitura (PICON-VALLIN, 2008). De modo semelhante, no final do mesmo século Peter Brook (1999) relatou o fracasso da sua tentativa de encenar a ópera Carmen, de Bizet, agindo como fizera Meierhold: adaptando o libretto e a partitura. No seu caso os patrocinadores do espetáculo e os proprietários do teatro recuaram ao saberem que a montagem não seria tradicional nem convencional. Embora não seja a preocupação deste artigo, é importante lançar um questionamento sobre a possibilidade ou impossibilidade de considerar a ópera como teatro se a hegemonia da pseudo tradição operística e da valorização do bel canto reforçar a disposição e o desejo de produzir, encenar e assistir sempre o mesmo do mesmo modo. Essa perspectiva é, ainda, reforçada quando deparamo-nos com relatos de jornalistas sobre as produções operísticas.

Ainda hoje as críticas ou revisões sobre as montagens operísticas trazem, via de regra, comentários negativos ou estereotipados sobre a encenação na ópera, demonstrando, na maior parte das vezes, desconhecimento sobre o que pode ser a encenação em ópera.

\section{O caso do Núcleo Universitário de Ópera - NUO}

Desde 2003 o Núcleo Universitário de Ópera (NUO) está presente na cena paulistana como uma companhia que visa à formação de jovens músicos para a ópera. 0 NUO é uma companhia de ópera estável, criada pelo maestro e compositor Paulo 
Maron. Com experiência no campo das artes e observando criticamente o panorama das produções operísticas no Brasil, Maron decidiu montar uma companhia junto a jovens cantores líricos aliados a uma orquestra formada por instrumentistas igualmente jovens, que também estavam em busca de novas experiências artísticas.

Os cantores, em geral, são músicos recém saídos das universidades de Música com habilitação em canto lírico ou ainda cursam os anos intermediários. Atualmente o maior contingente de estudantes advém dos cursos de música com habilitação em canto lírico da USP, UNESP e UNICAMP. Dos atuais vinte e cinco cantores, cerca de oitenta por cento estão nesta condição. O restante tem aulas particulares de canto ou, ainda, estuda nas escolas livres do estado e do município.

Anualmente a companhia apresenta dois repertórios: um dedicado às obras do século XX e outro voltado para a produção dos ingleses Willian Gilbert e Arthur Sullivan. Desde 2004 o NUO já protagonizou dezesseis montagens das quais quinze foram estréias nacionais. Em cada uma dessas produções o que a companhia propõe-se a fazer é buscar no teatro contemporâneo o referencial para a encenação. Para isso, mais de duzentas horas de ensaios e preparação são necessárias, distribuídas em quatro meses ininterruptos para as três récitas consecutivas que atendem a uma audiência média de 1200 pessoas.

A proposta da companhia é buscar no trabalho dos encenadores do teatro, como Grotowski, Meierhold e Brook, por exemplo, o tipo de encenação que se ajuste à vocação do espetáculo operístico. Nessa perspectiva é vital um trabalho corporal que conduza ao autoconhecimento e à ampliação de possibilidades de ações corporais para os artistas. Desde 2006 as técnicas de dança moderna (especialmente as técnicas e estudos propostos por Martha Graham, Rudolf Laban e Merce Cunnigham) e étnica (como o flamenco, odissi, kathak, africana) bem como a educação somática (especialmente o método Feldenkrais) são utilizadas de modo sistemático como parte da preparação dos cantores. A utilização e a organização das técnicas variam em função da característica da obra e da concepção cênica proposta pelo encenador e são consideradas as ferramentas para a materialização das intenções cênicas. Este trabalho é sempre fruto de um processo de investigação acadêmica e artística que envolve o encenador, a direção de arte e os artistas.

Como consequência do seu processo de trabalho o NUO tem sido procurado a cada semestre por jovens que assistiram às montagens anteriores ou por aqueles 
que ouvem falar do trabalho ali desenvolvido. Embora não haja qualquer remuneração para nenhum dos integrantes da companhia ${ }^{3}$, há uma constância importante na participação dos integrantes, bem como há crescente a procura por vagas a cada nova produção. Com frequência os integrantes apontam para a preparação cênica centrada no corpo do ator como espaço de encenação como o grande motivo para a manutenção de suas participações e para o ingresso na companhia.

Na declaração destes jovens músicos dispostos a buscar uma experiência teatral em ópera, parece haver uma posição crítica importante sobre o valor dado à encenação no gênero.

Mergulhada no cotidiano destes jovens e compartilhando das suas experiências na companhia, parece-me evidente que a construção de um conceito sobre encenação em ópera deve partir da reflexão dos artistas sobre o espetáculo operístico e sobre o lugar do corpo na encenação. Das reflexões postas anteriormente emergem questões que merecem ser respondidas: qual é o corpo que os jovens buscam durante a sua formação? A qual corpo eles se opõem? Por consequência, qual encenação é desejável em ópera? Qual não é? Desponta como última questão, decorrente das primeiras respostas, qual é o conceito de ópera desses jovens músicos, especialmente em relação às fronteiras entre o teatro e a voz cantada? Em última análise, qual é o lugar do corpo na ópera? Parece, assim, importante, buscarmos um caminho de investigação que nos conduza à construção e reflexão coletiva do conceito a partir da vivência cotidiana daqueles que buscam apropriar-se do seu corpo trazendo uma ampliação das suas possibilidades para a encenação.

No entanto, propor uma investigação dessa natureza é quase um caso de transgressão: como investigar o corpo e a encenação num universo ordenado pela Música?

Especificamente no caso da ópera, quando os estudos são realizados dentro e fora da área da Música, frequentemente o que está em jogo é a avaliação dos textos, o conteúdo do libretto, suas significações. É comum a opção por compreensões históricas do contexto das composições e/ou dos seus compositores, ou, ainda, reforçam-se as investigações no campo musicológico. Isso parece verdade especialmente quando

\footnotetext{
${ }^{3}$ Desde 2004 com a produção de The Mikado no Theatro São Pedro em São Paulo a companhia custeia as suas produções com o recebido pela bilheteria. A posição dos músicos e da direção foi, desde o início, garantir a produção seguinte ao invés de receber um pequeno cachê para cada montagem. Com o valor conseguido com a venda de ingressos, as taxas dos teatros e o pessoal técnico são pagos e, em geral, resta o capital de giro para a próxima montagem.
} 
buscamos referencial teórico acadêmico-científico nas bases de dados da música ou das artes cênicas em português, espanhol, inglês e francês. ${ }^{4}$

Apesar desta constatação, uma das organizadoras do I Simpósio Internacional de Musicologia da Universidade Federal do Rio de Janeiro ${ }^{5}$ afirmou, no texto de apresentação do evento, que:

Os estudos de ópera têm constituído um locus privilegiado das inovações ocorridas recentemente na musicologia, possibilitando abordagens diversificadas, desde estudos de sociologia, política, ideologia, história e crítica cultural, vocalidade e corpo até discussões sobre novas proposições analíticas para um gênero dramático musical que deve ser compreendido, sobretudo, como espetáculo (Volpe, 2010: 15).

No entanto, analisando o livro de resumos do evento foi possível constatar que das vinte e cinco conferências proferidas, apenas uma discutiu a questão da ópera como espetáculo e apontou para questões de natureza teatral enquanto as outras conferências transitaram entre a musicologia e a historiografia.

Nas palavras do professor Mário Vieira Carvalho, a ópera é comumente investigada no campo histórico e da musicologia, especialmente no que se refere aos compositores, aos intérpretes, às obras e às instituições $\mathrm{O}$ autor afirma serem necessárias investigações que compreendam o meio social e o impacto da produção operística nele e vice-versa, mas para ele é crucial pensar em formas de investigação da atividade artística para que seja possível o fomento à criação e interpretação inovadoras. Nesse caso, o papel daqueles que se propõem a encenar um espetáculo operístico é o de buscar meios de transformar o material da ópera numa experiência artística na qual o teatro e a eficácia teatral estejam lado a lado com a música: "não cabe à musicologia matar o teatro, mas sim ajudar a dar-lhe vida para um público do nosso tempo" (Carvalho, 2010: 35).

Não é apenas no Brasil que a investigação do espetáculo operístico ainda é incipiente. O antropólogo Paul Atkinson, da Universidade de Cardiff no Reino Unido, realizou um longo estudo etnográfico junto à Welsh National Opera buscando compreender o seu cotidiano. A principal publicação decorrente desta investigação - o livro Everiday arias: an operatic ethnography (2006) - é um dos raros trabalhos em que a ópera é estudada em movimento, no transcurso da realização das produções, no interior de uma

\footnotetext{
${ }^{4}$ Considera-se, ainda, como fonte de busca o Opera Quarterly, periódico publicado com regularidade pela Oxford Press, que apresenta em seus artigos com muita frequência a compreensão das composições ou dos seus compositores, ou, ainda, análise de obras específicas em profundidade do ponto de vista musicológico.

${ }^{5}$ O tema desse primeiro simpósio foi "Atualidade em Ópera" e teve como proposta fomentar o debate e a produção em torno desta temática (Cardoso, 2010).
} 
companhia estável e não como documento, ou como texto literário, como uma partitura musical, ou, ainda, como material para críticas jornalísticas, cujas análises vez por outra são publicadas em algum periódico ${ }^{6}$. O resultado é a compreensão do processo em sua essência, dos valores e atitudes compartilhados, de uma cultura sobre ópera, sobre a performance e o espetáculo; sobre a vida que se desenrola ali.

Em seu livro Ópera à brasileira o jornalista João Luiz Sampaio faz uma afirmação contundente sobre o desconhecimento que marca o meio operístico nacional:

\section{A memória da ópera brasileira está guardada apenas na lembrança daqueles que a viveram. Não há estudos sistemáticos que dêem conta do surgimento dos principais teatros, da maneira como evoluíram os modos de produção, da formação dos artistas e assim por diante (SAMPAIO, 2009:20).}

Embora não se possa exigir de um jornalista que seja feito um escrutínio sobre as produções disponíveis sobre o tema, e apesar de que é bastante provável que haja algum material produzido nos meios acadêmicos que seja desconhecido do referido autor, sem dúvida é importante considerar a sua afirmação. Num campo onde há poucas iniciativas estáveis de produção cultural e de formação de artistas como é o caso da ópera, um estudo da natureza proposta neste artigo aponta para a construção de um corpo de conhecimentos que permita compreender aspectos da ópera no Brasil.

Tendo como suporte os estudos de Atkinson (2006) e a afirmação de Carvalho (2010) e a reflexão contínua dos jovens músicos que se preparam para a cena operística parece fundamental refletir sobre a urgência das investigações in loco no campo da produção operística. Nas palavras do antropólogo (ATKINSON, 2004; 2006) a vivência determinada pela produção do espetáculo operístico deve ser reconhecida, conhecida e compreendida como um espaço de criação de cultura. A vivência no cotidiano implica em compartilhamento de valores culturais, experiências pessoais e significados e, portanto, as pessoas envolvidas muitas vezes modificam os seus modos de ver e de estar no mundo. Compreender, então, o cotidiano, os valores e significados da vivência numa companhia de ópera pode ser um caminho para o início de produção de conhecimento sobre determinados aspectos deste gênero no Brasil. Por trás dessa inquietação há uma indagação sobre o que é a ópera: esta resposta

\footnotetext{
${ }^{6}$ No jornalismo brasileiro o crítico Lauro Machado Coelho é o referencial claro e presente, tanto das críticas publicadas no jornal paulistano O Estado de São Paulo, quanto em seus livros que relatam as óperas nos diferentes países e suas montagens no Brasil. De outro modo os documentos elaborados pelo professor Sérgio Casoy, que tem acompanhado a Ópera em São Paulo, de forma sistemática e presencial, registram as fichastécnicas dos espetáculos realizados na cidade ou, ainda, comentam a obra, o contexto histórico e os autores da ópera que foi executada.
} 
está nas teorizações, mas é divergente no discurso dos cantores? Em qual medida a ópera é teatro? Qual teatro ela é? O teatro da palavra? O teatro musicado? Por outro lado, essas definições e conceitos estão à mercê da disponibilidade do cantor/ator de ópera? Qual, então, é o lugar do corpo na ópera?

A partir daqui essas reflexões tomam a forma de uma pesquisa participante. Nessa modalidade de pesquisa, pesquisadores e pesquisados realizam um trabalho em comum: são atores num mesmo cenário. O que se pretende com este tipo de pesquisa é construir coletivamente um conhecimento, a partir de uma verificação atenta daquilo que está emergindo no grupo e que, pela reflexão crítica e coletiva, pode tomar corpo e influenciar positivamente os modos de ser e viver de uma dada comunidade. O pesquisador deve estar de antemão comprometido legitimamente com a causa do grupo, com a sua tarefa cotidiana e deve também ser reconhecido pelo grupo como alguém com quem o projeto se desenvolve conjuntamente. É ele o responsável por identificar aquilo que emerge do grupo pesquisado e que se torna objeto da investigação e a partir daí propõe uma investigação para o grupo (SCHMIDT, 2006).

A definição das técnicas e procedimentos de busca de dados e sua divulgação para os participantes da pesquisa são definidas na ação coletiva e devem compor uma espiral, na medida em que possam aumentar as possibilidades de reflexão, de novas conversas e diálogos que produzem mais resultados e, por sua vez, ampliam as reflexões (BRANDÃO, 1990).

Considerando que todas essas características necessárias já estão presentes na relação pesquisadora-grupo, o presente projeto se desenvolverá durante a preparação para Os Gondoleiros, de William. Gilbert e Arthur Sullivan, que estreará no mês de dezembro de 2011 e Fairy Queen de Henry Purcell que terá sua estréia em junho de 2012. Os ensaios serão realizados duas vezes por semana, durante três horas por dia, num espaço alugado pela companhia, no bairro da Liberdade, em São Paulo.

Num campo onde há escassa produção acadêmica e científica, a busca pela narrativa, pela experiência, pelos valores, pela tradição e pela inovação vivenciadas são os alicerces para a compreensão da cultura que está sendo construída e que pode nos levar a uma compreensão inicial sobre o lugar do corpo na encenação em ópera

\section{Referências}

ATKINSON, P. Everyday Arias: na operatic ethnography. Oxford: Altamira Press, 2006.

Performance and the rehearsal: the etnographer at the opera. In: SEALE, C.; GOBO, 
G. GUBRIUM, J.F.; SILVERMAN, D. Qualitative Research Practice. London: Sage Publications, 2004.

BRANDÃO, C. R.(Org.) Pesquisa Participante. 8ª̃d. São Paulo. Brasiliense, 1990

BROOK, P. A porta aberta. São Paulo: Civilização Brasileira, 1999.

CARDOSO, A. Ópera em cena da UFRJ In: VOLPE. M.A. (Org.) Atualidade da Ópera. Livro de resumos. I Simpósio Internacional de musicologia da Universidade Federal do Rio de Janeiro. UFRJ, 2010 (p.35).

CARVALHO, M.S. Ópera na história e na actualidade: uma perspectiva sociológica. In: VOLPE.M.A. (Org.) Atualidade da Ópera. Livro de resumos. I Simpósio Internacional de musicologia da Universidade Federal do Rio de Janeiro. UFRJ, 2010 (p.11).

CASOY, S. A ópera em São Paulo: 1952-2005. São Paulo: Edusp, 2006.

Contos de óperas e cantos. São Paulo: Algol, 2009.

Trajetórias: anotações sobre um século de ópera brasileira. In: SAMPAIO, J. L. (Org.) Ópera à brasileira. São Paulo: Algol, 2009 (p.23-34).

COSTA, L. As velhas amas das óperas venezianas seiscentistas: um elo entre o teatro falado e cantado. PerMusi - Revista Acadêmica de Música, n¹7, 2008 (p.26-31).

DUDEQUE, N. O drama wagneriano e o papel de Adolphe Appia em suas transformações cênicas Revista Científica./FAP, Curitiba, v.4, n.1 p.1-16, jan./jun. 2009.

GUSE, C.B. O cantor-ator: um estudo sobre a atuação cênica do cantor na ópera. Instituto de Artes da UNESP, 2009. Dissertação (Mestrado em Música).

PEIXOTO, F. Ópera e encenação. São Paulo: Paz e Terra, 1986.

PEREIRA, M.S. Cinema e ópera: um encontro estético em Wagner. Escola de Comunicações e Arte da Universidade de São Paulo, 1995. Dissertação (Mestrado em Cinema).

PICON-VALLIN, B. A arte do teatro: entre tradição e vanguarda - Meyerhold e a cena contemporânea. (tradução de Cláudia Fares, Denise Vaudois e Fátima Saadi). Rio de Janeiro: Letras e Imagens, 2006.

A Cena em ensaios. São Paulo: Perspectiva, 2008.

Meyerhold: les voies de la création théâtrale. Paris: CNRS Editions, 1999 (Tome 17).

ROUBINE, J.J. A linguagem da encenação teatral. $2^{\mathrm{a} E d}$. Rio de Janeiro: Zahar, 1998.

SAMPAIO, J.L. (Org.) Ópera à brasileira. São Paulo: Algol, 2009.

SCHMIDT, M.L.S. Pesquisa participante: alteridade e comunidades interpretativas. Psicologia USP. São Paulo: IPUSP, 2001, 17 (2) (p.11-41).

STANISLAVSKI, C; RUMYANTSEV, P. Stanislavski on opera. (translated by Elizabeth Hapgood). New York: Routledge, 1999.

VOLPE, M.A O Simpósio Internacional de Musicologia e a atualidade na ópera. IN:VOLPE, M.A. (Org.) Atualidade da Ópera. Livro de resumos. I Simpósio Internacional de musicologia da Universidade Federal do Rio de Janeiro. UFRJ, 2010.

\section{Outros links úteis}

The Opera Quaterly 